where the skin was scratched or otherwise broken, or even where exposed to the irritation of the clothing long wet with salt water. I should say that up to Batavia and beyond we had been using Loch Katrine water, supplemented by a small supply from Plymouth, both being of unquestionable quality. Any probable intention of taking in a further supply from the port of Batavia, where we coaled, was at my suggestion entirely abandoned by the captain, especially as he had there been apprised, by telegram, of the occurrence of cholera on the Dorunda some time after leaving the port at which we then were; and, in fact, a message had been sent prohibiting the entrance of vessels proceeding to Queensland ports within the harbour of Batavia in consequence of that circumstance, but it arrived too late to admit of the captain's compliance with the order. We were then under the necessity of condensing the sea-water, a task which the chief engineer readily undertook.

In view of the epidemic character of the symptoms of colic and abdominal cramps, one of the engineers suggested the possibility of the zinc plates which were fixed in the "donkey boiler"-whence our supply of water for drinking purposes was condensed - in order to prevent the corrosion of the iron as being the cause-an idea, I may say, not favourably received by some others. I thought it advisable, however, to procure a sample of the water in order to test it for the presence of zinc, which 1 accordingly did. I may say that the weather was hot and wet, and the quantity of water consumed, especially by the poor firemen in their arduous toil, in the shape of meal and water, was unusually large. In the process of galvanising, or coating iron with zinc, the latter metal not only acts as a varnish or protective, but becomes oxidised, as you are aware, before the iron is so acted upon, even though its surface be exposed. L. L'Hote, in "Comptes Rendus," says: "As to the inquiry if zinc free from any foreign metal decomposes water either on boiling or in presence of dilute sulphuric acid, experiment proves that such is not the case. Pure zinc heated with distilled water in a flask, so arranged as to receive the gases over mercury, gives off no hydrogen on prolonged boiling, nor is it attacked by dilute sulphuric acid. The presence of iron in the proportion of 3 to 5 in 100,000 enables it to decompose water. Traces of arsenic and antimony have the same effect."

On my return home, and having leisure to prosecute the inquiry, I find, on evaporating a portion of the water in question and testing it, there is decided evidence of the presence of zinc. Hence it will, I think, appear evident that the presence of zinc plates in iron boilers used for condensing water for human consumption is fraught with danger to the health, if not, indeed, to the life, of those consuming the water for any length of time. Although in the case of the ship in question, intended for the coasting trade of Australia, it is probable that condensed water will not often be used, and although unhappily the quality of the water obtainable at some of the ports on that coast is not of the best, and will not suffer from boiling before being drunk, yet the subject, embracing also the very general use of galvanised iron under similar circumstances, I think you will be prepared to admit, is well worthy the attention of those concerned, and, as in cases similar to the above, of investigation by the Board of Trade.

I am, Sir, yours faithfully,

$$
\text { JOHN WARD, M.D., }
$$

Sutton Coldfield, Birmingham, Ex-Medical Officer of Health. April 12th, 1886 .

\section{LAW AND LUNACY.}

To the Editor of TH LANCET.

SIR,-As a forcible illustration of one of the social phases of the deleterious consequences arising from the recent prosecutions of medical practitioners for giving certificates of insanity, I venture to forward to you a few extracts from a letter my wife received from a lady friend this morning. They appear to me to be so brimful of materials for reflection, alike to doctors, lawyers, and the general public, that they ought to be made known. I give the extracts in the lady's own words, for although the language she employs is simply that of a friendly letter, it seems to me to be quite telling enough, and will possibly be all the more impressive by reason of its very simplicity. I suppress, of course, the name of the writer, and as the extracts from her letters are forwarded to you without her knowledge, I hold myself responsible for them. They are as follows:-

"My husband's illness from overwork has taken a very serious turn, after apparent complete restoration. $\mathrm{He}$ has some form of brain mischief which makes him believe that he is very rich, and he has been buying everything he fancies for a year past, including land, and entering into terrible expense connected with railway-making. He will take no advice, and I have been consulting doctors in vain for months hoping to get help to protect him from those preying upon him. But, alas! from the state of the law and the fears medical men are in of the consequences, it has been all in vain, though they admit the need. All his property is involved now; our home is sold up, and our pretty things have all been ruthlessly squandered by a forced sale. I see no end of my troubles, for Mr. — considers himself still as rich as ever, and is so angry at me for doubting it that 1 hardly dare go to him. At present I have no home to go to, except to one of his country farm-houses, where he had furnished a part for ourselves."

These extracts are, I think, sufficient to show how recent. actions against alienists is beginning to react against the general public, and when viewed in association with Lord Shaftesbury's sad suicide prove that the present state of the Lunacy Law as regards the responsibilities of medical men in signing certificates requires immediate emendation. ${ }^{{ }^{1}}$ For while Lord Shaftesbury destroyed his own life, here, in the above-mentioned case, the gentleman destroys the means not only of supporting his life, but that of his family. Every medical man knows how often a few months of wellregulated restraint will suffice to cure an attack of monomania, and how that the individual after recovery may enjoy many long years of comfort and happiness. He equally knows that it is exceedingly rare for any of these cases, except during the incubation period, to possess either suffcient mental power or moral strength to voluntarily place himself under restraint, while the medical treatment of monomania involves quite enough of anxiety without having the additional terrors of the law superadded to it. If Lord Shaftesbury's and the above-described case be not examples of true insanity, my notions of mental disease and moral responsibility, I fear, require important revision.

I am, Sir, faithfully yours,

Harley-street, Cavendish-square. GRoRGE HARLwY, M.D.

\section{THE PERILS OF SUBCUTANEOUS MEDICATION.}

\section{To the Editor of THE LANCET.}

SIR,-Having just heard from Dehra-Dûn to the effect that my old friend and quondam companion in some Himalayan rambles, Frederick Wilson, Esq., better known as "Shikari" Wilson, died at Mussoorie in July, 1883, of what. would appear to be an over-dose of morphia, subcutaneously injected, I wish to take this opportunity of calling attention to the subject, and of intimating at the same time that two such cases of this description have occurred within the sphere of my own individual cognisance. I am precluded by personal or professional reasons from entering into any details respecting these, and I merely alluded to them here to enable me to offer it as my opinion - an opinion which, as you, I think, know, is based on something better than books-that this form of poisonous drug administration is fraught with the greatest danger in that most weakening: or worrying malady-frequently recurring or chronic, suppressed, or systemic-gout.

As regards the case of my poor friend, and making all due allowance for the feelings or the exaggeration of a son, the circumstances under which be succumbed are briefly as follows:- " He had just returned (says my informant) from Gungostre - the source of the Ganges-suffering, as usual, from his old enemy the gout. As the pain became intense, - was called. in, and he carelessly injected an overdose of morphia, for my poor father never recovered from the deep sleep it produced, but died about three hours after the injection." And had the Emperor Charles V. or the great Earl of Chatham, who were both undoubtedly victims to this disease, been similarly treated during any of their paroxysms, the history of the Spanish Armada or of the French fleet

1 This necessity has already been represented in a letter signed "General Practitioner," published in THE LANCET of March 6th last.FD. $\mathrm{L}$. 